\title{
The design of intelligent electronic relay based on AT89C52 single chip microcomputer
}

\author{
Ke Yuan
}

Nanchang Institute of Science \&Technology, Institute of Electrical and Information Engineering

Keywords: Single chip microcomputer, Intelligent electronic, Relay

\begin{abstract}
Using AT89C52 single chip microcomputer to complete the design of the intelligent electronic timing relay, not only can well realize the arbitrary set of time, but also can be accurate to milliseconds. This design from the total block diagram of hardware design, described the design of hardware and software in detail, and gave the design of the circuit principle diagram, hardware diagram and program code.
\end{abstract}

\section{The function module of the intelligent electronic relay}

In order to realize the function of the intelligent electronic relay, this design used six modules (see figure 1).

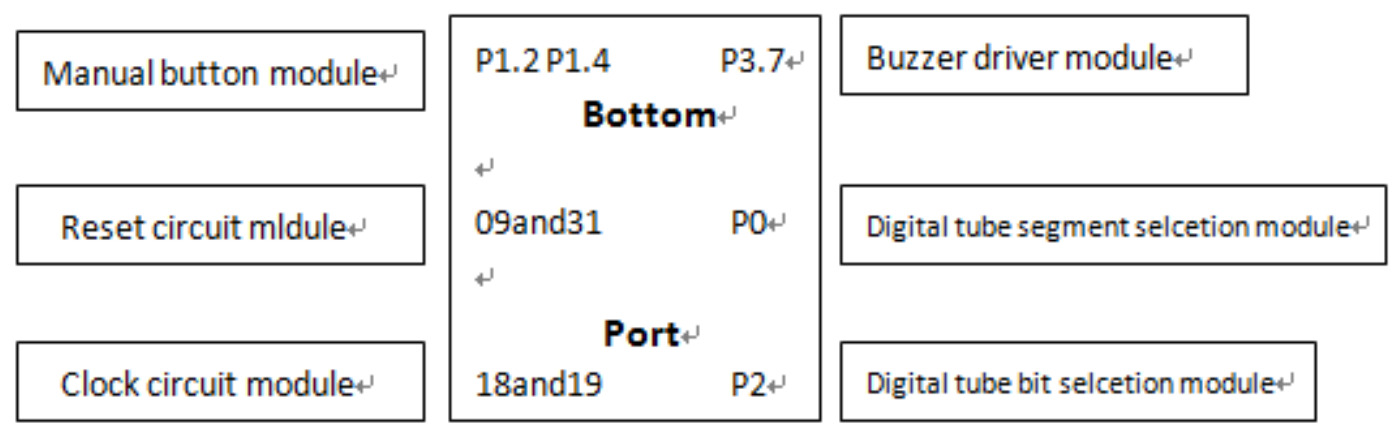

Figure 1 Intelligent electronic relay module diagram

(1) The design of reset circuit module

In order to ensure the circuit works stably and reliably in microcomputer system, reset circuit (see figure 2) is an essential part, the function of the reset circuit is power on reset. General microcomputer circuit works normally need power supply for $5 \mathrm{~V}+5 \%$, namely from $4.75 \mathrm{~V}$ to $5.25 \mathrm{~V}$. Because the microcomputer circuit is sequential digital circuit, it needs stable clock signal, therefore, when the power on, only when VCC more than $4.75 \mathrm{~V}$, less than $5.25 \mathrm{~V}$ and crystal oscillator works stably, reset signal can be removed, the microcomputer circuit begin to work normally.

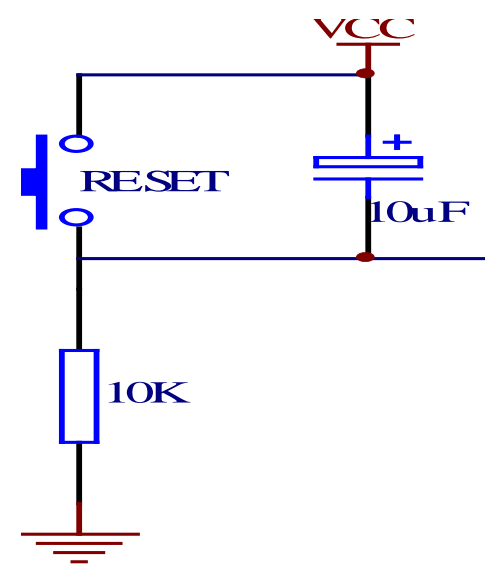

Figure 2 Reset circuit

The working principle of reset circuit: when VCC is powered on, C1 is charging, appears the 
voltage in the $10 \mathrm{k}$ resistor, makes the single chip microcomputer reset. A few milliseconds later, $\mathrm{C} 1$ is full of electricity, the current on $10 \mathrm{k}$ resistor drop to zero, voltage is also zero, makes the single chip microcomputer into the working state. During the work, press the reset button, C1 is discharging. Loosen reset button, C1 is charging again, appears the voltage in the $10 \mathrm{k}$ resistor,makes the single chip microcomputer reset. A few milliseconds later, the single chip microcomputer into the working state.

(2) The design of clock circuit module

Clock circuit (see figure 3) is an oscillating circuit that is as accurate as a clock, any work in chronological order, the circuit used to generate this time is the clock circuit.

This clock circuit uses a 11.0592 MHZ crystal oscillator and two 30P capacitance, is the key link of single chip microcomputer, to provide accurate timing function for single chip microcomputer.

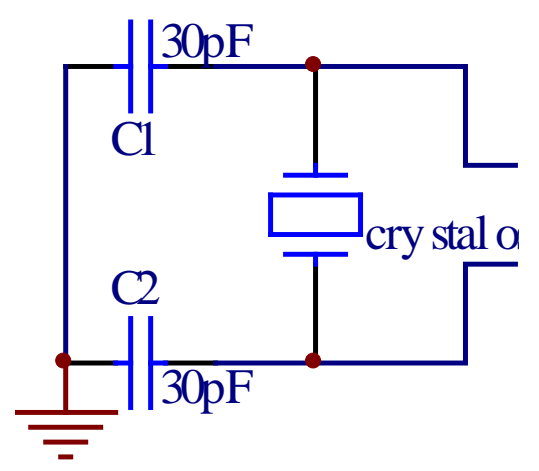

Figure 3 Clock circuit

(3) The design of buzzer driver module

This design uses the mode of I/O port timing flip level drive buzzer, drive circuit (see figure 4), the specific driver see the next chapter. As a result of the working current of buzzer compared ordinary is large, so that the I/O port of single chip microcomputer can not be directly driven, so need use amplifier circuit to drive, generally use the triode to amplify current.

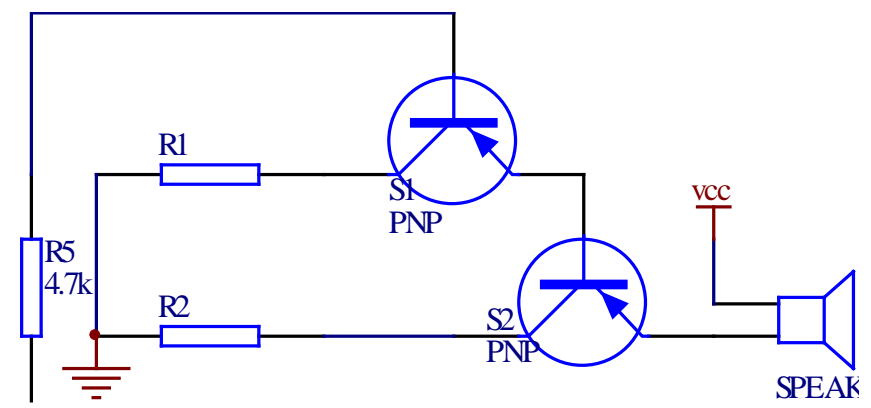

Figure 4 Buzzer driving circuit diagram

(4) Digital tube segment selection module

Digital section selected, that is, when the single chip microcomputer output the glyph code to the I/O port, eight display strokes "a, b, c, d, e, f, g, dp" of digital tube are lighted up as required. 
Such as output the glyph code 0 x06, digital tube "a, b, c, d, e, f" are lighted up, shows "0".

(5) Digital tube bit selection module

Digital tube bit-strobe is controlled by separate I/O lines, when the single chip microcomputer output the glyph code, all the digital tubes receive the same glyph code, but what is the digital tube will display the glyph, depends on the control of single chip microcomputer to bit-strobe COM terminal circuit, so we just need to open the strobe control of single chip microcomputer which will be displayed, it will show the glyph, no strobe digital tube will not light.

\section{The design of the software}

The software of this design mainly includes: start, digital tube display program, buttons receive program and buzzer control program. As shown in figure 5:

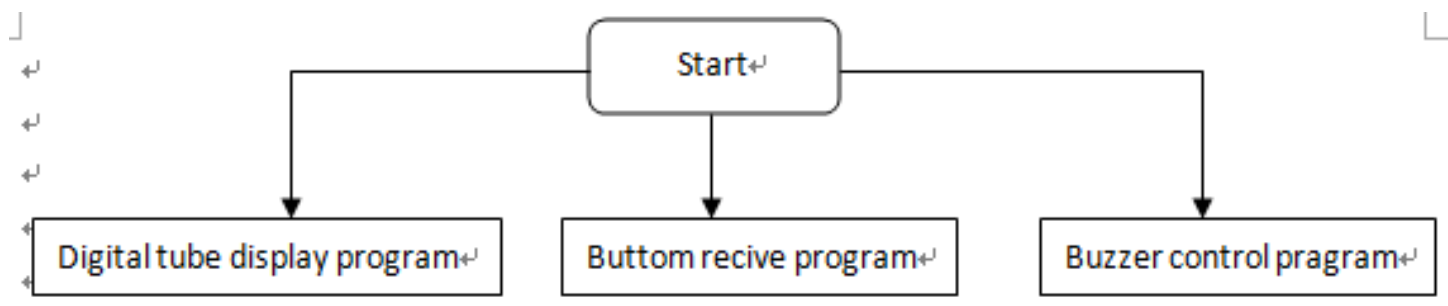

Figure 5 The function module of software

This design uses the timer of AT89C52 single chip microcomputer to carry on the design, by the single chip microcomputer clock circuit, crystal oscillator frequency is $11.0592 \mathrm{MHZ}$, that is the cycle is 1 us. Specific arrangements are as follows:

(1) With the working mode of AT89C52 (that is 16 bit timer).

(2) The digital tube uses dynamic display, P0 port uses segment selection, P2 port uses bit selection. Because digital tube is a total of anode, segment code 0-9 is 0xc0,0xf9,0xa4,0xb0,0x99,0x92,0x82,0xf8,0x80,0x90,0xcf, but bit selection is 0xfe,0xfb,0xef,0xbf.

(3) Because the digital tube display too fast, the naked eye has not had time to react and then went out, so need to add a delay program.

(4) Due to the speed of single chip microcomputer in microsecond level, when the button is pressed there will be a misoperation, and even make a mistake, so you need to shake, generally use the method of judging first, following the delay 5-10 ms and judging again.

\section{The debugging of the software}

Using the software of kell uvision2 to debug, below is picture after debugging success: 


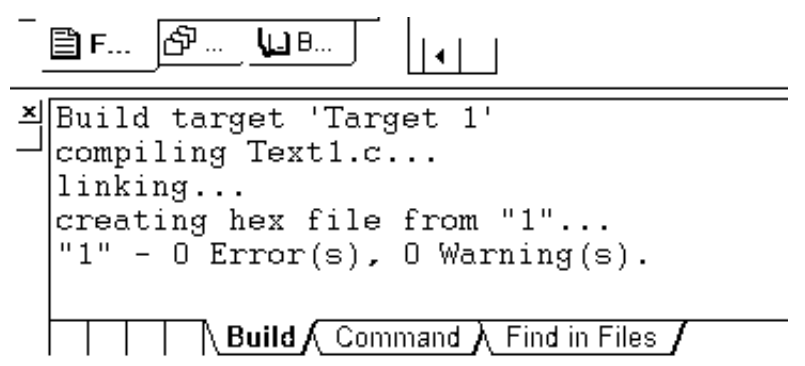

Pay attention to the problems in the process of debugging:

(1) Should include what headers and their writing format.

(2) Ensure the correctness of the keywords input.

(3) Must be written procedures in letter input mode, especially the ";", if input under text input mode, you will make mistakes.

(4) The size of programs written in the software of kell uvision2 has an upper limit, more than you can not debug.

\section{References}

[1]Furong Lei, Xiaolin Zhang, Hao Cui. The query manual of 51 single chip microcomputer common module design [M]. Beijing: Tsinghua University press, 2010.1.

[2]Xianyong Wang, Longyuan Guo. The principle and application of single chip microcomputer [M]. Beijing: Science press, 2011.

[3]Lingong Li. The principle and application of single chip microcomputer (second edition) [M]. Beijing: Science press, 2013.2. 